\title{
CYTOLOGY, GENETICS AND CLASSIFICATION
}

$\mathrm{A}^{\mathrm{N}}$

N all-day discussion on September 4 on "Cytology and Genetics in Relation to the Classification of Plants and Animals" was arranged by Sections D (Zoology) and $\mathbf{K}$ (Botany) of the British Association during the Birmingham meeting. The morning session dealt mainly with animal organisms and the afternoon session with plants.

Mr. S. Muldal (John Innes Horticultural Institution) opened the morning discussion with a general paper on earthworm cytology. The British earthworm fauna comprises the genera Allolobophora (five species), Lumbricus (five), Eisenia (three), Eiseniella (one), Dendroboena (four), Bimastus (four), Octolasium (two) and Eophila (one). There are generic differences with regard to cocoon production by unmated worms, there being species with no cocoon production (Allolobophora), infertile only (Lumbricus), and fertile cocoons (in most other genera). It appears that the mode of reproduction varies from the strictly crossbreeding species such as the British Allolobophora and Lumbricus species to the obligate parthenogenetic Octolasium cyaneum $(8 x)$, Eiseniella tetroedra $(4 x)$, Eisenia rosea $(3 x)$ and Bimastus tenuis $(3 x)$. The chromosome number is constant in Lumbricus, $n=18$, which is probably the primitive basic number for the family. In Allolobophora there are two basic numbers, 18 and 16. In Dendrobana the basic number is 17, in Bimastus 16, in Octolasium 19, in Eisenia 11 and 18, and the subspecies examined of Eiseniella tetroedra have $2 n=72$, with 18 as probable basic number. The latter have probably developed from the polymorphic Eisenia venata.

All the polyploid worms show obligate parthenogenesis. They are highly successful species, peregrine and cosmopolitan, and exhibit less variation than do the sexual species. It is a general belief, Mr. Muldal said, that polyploidy is very rare in the animal kingdom, but at the moment we have little evidence on which to base this assumption. Large groups of animals are still not examined, and the numbers included in the chromosome lists are often from widely separated species. Only by working through relatively young animal families, like the Lumbricidæ, can one assess the part played by polyploidization in speciation. Old polyploidy, from a phylogenetic point of view, is, however, often impossible to discover in our present animals, since older types with lower multiples may be altogether extinct.

Dr. B. N. Singh (Rothamsted Experimental Station) has studied nuclear division in small freeliving amcebr and its bearing on their classification. The free-living amobæ have previously been classified largely on the basis of nuclear structure and mode of division. Extraordinary differences in the behaviour of the nuclear constituents have been claimed, and the consequent confusion has been due to two principal causes : the difficulty of getting the various normal stages of nuclear division, owing to lack of suitable cultural conditions ; and the use of Hæmatoxylin or other non-specific dyes for showing the nuclear structure and behaviour. A detailed study of the effect of varied bacterial food has led to the development of a standard culture method. This enables one to get all the stages of division in young and healthy specimens. The division of twelve strains of amcbæ, consisting of at least nine distinct species, has been studied.

The use of the Feulgen reaction has shown that the resting nucleus of all the species contains Feulgenpositive granules, which give rise to chromosomes during division. The karyosome (nucleolus) does not contain Feulgen-positive chromatin, nor does it give rise to chromatin at any stage. This brings the mode of nuclear division in line with that in higher animals and plants.

According to their mode of division the amœbæ can be arranged in two groups. In one, the karyosome persists throughout division, whereas in the other it disappears. Such a diversity was not apparent in the earlier works.

The next contribution to the discussion was a paper read by Mr. L. Sachs (School of Agriculture, Cambridge) on cytogenetics in relation to the systemation and phylogeny of the Triticinæ.

The Triticinæ (Gramineæ) contains the genera Aegilops, Agropyron, Haynaldia, Secale and Triticum, with a total of well over a hundred species. In a comparison of the different methods of investigating the systematics and phylogeny the following modes of approach were discussed and illustrated: gross morphology, chromosome number and morphology, chromosome pairing and fertility in interspecific and intergeneric hybrids, chromosome pairing and fertility in colchicine-derived amphidiploids, the genetic behaviour of certain characters, and the attempted artificial synthesis of existing species.

In the analysis of chromosome pairing in hybrids, Mr. Sachs discussed the genome concept, and evidence was presented to show the desirability of revising the accepted genome formula for the tetraploid species 1 riticum timopheevi. In the discussion on interspecific and intergeneric amphidiploids, it was also suggested that, although some of these are morphologically distinct and reproductively isolated new 'species' or even new 'genera', they should not be given new specific or generic names, but rather formulæ in order to show their experimental origin. The methods of comparative genetics were illustrated by the action of interspecific and intergeneric lethals and sublethals associated with a hexaploid species of Triticum. Each of the five genera has evolved in its own way, either by instantaneous speciation brought about by polyploidy or the presence of interspecific lethals, or by gradual speciation brought about by accumulation of gene and chromosome changes.

The last speaker was Dr. J. P. Harding (British Museum ( $\mathrm{Na}$ ural History)), who gave a review of the cytology of some Crustacea as an aid to their classification. $\mathrm{He}$ said that consideration of the chromosome numbers of copepods indicates that the more primitive members have the highest numbers. The Calanoida is the most primitive sub-order and the haploid number is nearly always 16 or 17 , whereas in the other sub-orders it is rarely more than 12 and may be as low as 2 . In Cyclopoida also the highest numbers are found in the more primitive species.

Three ctosely related species, Cyclops fuscus, $C$. albidus and $C$. distinctus, occur in Great Britain, often in the same body of water. $C$. distinctus is on the 
whole intermediate between the other two both in its morphology and in its ecological preferences, and many. workers have considered it to be a hybrid between them. In both fuscus and albidus, seven bivalents are found in the oocyte, those of albidus being distinctly smaller than those of fuscus. In distinctus the chromosome number is variable, which indicates its hybrid nature. Breeding experiments do not give direct support to this, for the three forms breed true and are completely intersterile. C. dis. tinctus seems to be a good species of hybrid origin.

Closely related species of Cyclops may have different chromosome numbers. $C$. vernalis, $C$. parcus and $C$. brevispinosus are so similar that most systematists make no attempt to separate them; their haploid numbers are, however, 5,3 and 2 respectively.

The true nature of breeding systems can in most cases be assessed only by cytological study, and their determination is a decisive step in working out the systematics of a group. The chromosome number is also an additional morphological characteristic of which too little use has been made so far. The discoveries made with the aid of these newer tools will be of great importance in revising the 'old systematics'.

S. MULdaL

The first speaker at the afternoon session was Prof. T. J. Jenkin, who described his extensive experimental work on the grass genera, Lolium and Festuca. Two groups of species, all diploid $(2 n=14)$, can be distinguished in Lolium : one, which is selfpollinated, comprises $L$. temulentum, $L$. remotum and $L$. lotiaceum; and the other, which is cross-pollinated, $L$. perenne, $L$. rigidum and $L$. italicum. Within each group more or less fertile interspecific hybrids can be made ; and viable hybrids can also be made between members of each group. Among factors which may have been responsible for speciation, involuntary human selection for seed size in $L$. temulentum, a weed of cereals, and in $L$. remotum, a weed of flax, was mentioned as an interesting possibility. Festuca is a larger and more widely distributed genus, and contains polyploid as well as diploid species ; two groups, narrow-leaved forms such as $F$. capillata $(2 n=14)$, $F$. ovina $(2 n=28)$ and $F$. rubra $(2 n=42)$ and broad leaved forms such as $F$. pratensis $(2 n=14), F$. arundinacea $(2 n=42)$ and $F$. gigantea $(2 n=42)$, can be distinguished. Again, hybridization within each group is possible, though the hybrids are often malesterile; but the only hybrid linking the two groups directly is $F$. rubra $\times F$. arundinacea, which is weak vegetatively and has never flowered. An indirect link is provided through Lolium perenne and $L$. loliaceum, both of which have been successfully crossed with both groups of fescues. These experiments, and the cytological investigations which have been made on the hybrids, clearly have an important bearing on the taxonomy and phylogeny of the genera.

Colonel F. C. Stern, who spoke next, gave several examples of the uses of chromosome number and morphology in solving taxonomic problems; he illustrated his remarks by means of excellent maps. First, in the genus Pceonia, the European members can be divided into groups, each containing diploid and tetraploid species. Not only do the chromosome numbers here form an invaluable guide to the taxonomist in distinguishing closely allied forms, such as $P$. Cambessedesii (Balearic Is., $2 n=10$ ) and $P$. Russi var. leiocarpa (Corsica, $2 n=20$ ), but they also provide a clue to the phylogeny of the group; it is likely that the diploid forms are the isolated relics of preglacial populations, and that the tetraploids, with their wider and more continuous distribution, have developed in inter-and post-glacial times. Secondly, in Primula section Farinosce, subsection Eu-farinosæ, chromosome counts facilitate the distinction of species otherwise almost indistinguishable morphologically, such as $P$. scotica $(2 n=54)$ and $P$. scandinavica $(2 n=72)$, and also give an illuminating guide to the relationships of the many polyploid species. The possibility that the circumpolar $P$. stricta, with 126 chromosomes, is an allopolyploid derived from species with 54 and 72 chromosomes, was mentioned. Thirdly, the chromo. some number and morphology of the genera Galanthus and Leucojum were discussed; in Leucojum the basic numbers $n=7,8,9$ and 11 are known and most of the species are tound at the western end of the Mediterranean. In Galanthus, practically all the species have $n=12$, and most of the species are found at the eastern end of the Mediterranean and in the Caucasus. It was suggested that the two genera had both been derived from an ancestral European stock that had been split into two parts as a result of glaciation; in this connexion, the close resemblance between Leucojum vernum $(n=11)$ and species of Galanthus was pointed out. It was also shown that breakage or fusion of chromosomes, as in Fritillaria, may have been an important factor in speciesformation in Leucojum. Finally, examples were given of the use of cytology in tracing phylogenetic lines (in Crepis) and in deciding between alternative taxonomic arrangements (Yucca and Agave).

The correlation between morphology, chromosome number and geographical distribution was further developed in the next paper, by Dr. E. K. JanakiAmmal, on polyploidy in the genus Rhodcdendron. After referring to the early work of Sax, who had suggested that this genus consisted mainly of diploids, with $2 n=26$, Dr. Janaki-Ammal described her own recent investigations, which have covered the fortythree sections into which Hutchinson has divided the eight hundred species of the genus. The cytological results can conveniently be summarized under three main groups. First, the Azalea group, with a wide distribution in the northern hemisphere, is diploid except for two tetraploid species in North America. Secondly, the non-lepidote group, comprising among others the well-known tree rhododendrons of our gardens, is exclusively diploid; 146 species of this group, which is found mainly in Eastern Asia, have been examined. Thirdly, the lepidote group, composed mainly of montane Himalayan species, contains a very high proportion of polyploids, with chromosome numbers ranging from 52 to 156 . The interesting point was made that the circumpolar $R$. lapponicum is always diploid, while its Himalayan relatives are polyploid. These new observations will obviously contribute very greatly to our understanding of the genus Rhododendron.

In the fourth paper, Prof. D. H. Valentine spoke about the use of interspecific compatibility as a taxonomic criterion. He began by defining the 'comparium', which is a group composed of all those species which can be united, directly or indirectly, by hybridization; this unit, which was first proposed 